outer cortical regions with ipsilateral CPUO in Group I suggests the action of circulating vasoconstrictors. In contrast, distribution of RBF to inner cortical regions following uninephrectomy and severe CPUO in Group II may be due to the opposing actions of vasodilators. A better understanding of the factors underlying changes in glomerular perfusion patterns during CPUO in early development may lead to better preservation of renal function in infants with congenital obstructive nephropathy.

Acknowledgments. Ms. Jean De Piro provided secretarial assistance.

\section{REFERENCES}

1. Chevalier RL 1982 Functional adaptation to reduced renal mass in early development. Am J Physiol 242:F190

2. Chevalier RL 1982 Glomerular number and perfusion during normal and compensatory renal growth in the guinea pig. Pediatr Res 16:436

3. Chevalier RL 1983 Hemodynamic adaptation to reduced renal mass in early postnatal development. Pediatr Res 17:620

4. Chevalier RL Chronic partial ureteral obstruction in the neonatal guinea pig. II. Pressure gradients affecting glomerular filtration rate. Pediatr Res 18:1271

5. Clausen G, Tyssebotn I, Kirkebo A, Ofjord ES, Aukland K 1981 Distribution of blood flow in the dog kidney. III. Local uptake of $10 \mu \mathrm{m}$ and $15 \mu \mathrm{m}$ microspheres during renal vasodilation and constriction. Acta Physiol Scand 113:471

6. Griscom NT, Vawter GF, Fellers FX 1975 Pelvoinfundibular atresia: the usual form of multicystic kidney: 44 unilateral and two bilateral cases. Semin Roentgenol 10:125

7. Harris RH, Yarger WE 1974 Renal function after release of unilateral ureteral obstruction in rats. Am J Physiol 227:806

8. Hinman F 1923 Renal counterbalance: an experimental and clinical study with reference to the significance of disuse atrophy. J Urol 9:289

9. Ichikawa I, Brenner BM 1979 Local intrarenal vasoconstrictor-vasodilator interactions in mild partial ureteral obstruction. Am J Physiol 236:F131

10. Josephson S, Wolgast M, Ojteg G 1982 Experimental obstructive hydronephrosis in newborn rats. II. Long-term effects on renal blood flow distribution. Scand J Urol Nephrol 16:179

11. Kleinbaum DG, Kupper LL 1978 Applied Regression Analysis and Other Multivariable Methods. Duxbury Press, North Scituate, MA, pp 97-102

12. Merrell RW, Mowad JJ 1979 Increased physical growth after successful antireflux operation. J Urol 122:523

13: Moody TE, Vaughan ED Jr, Gillenwater JY 1977 Comparison of the renal hemodynamic response to unilateral and bilateral ureteral occlusion. Invest Urol 14:455

14. Morkrid L, Ofstad J, Willassen Y 1978 Diameter of afferent arterioles during autoregulation estimated from microsphere data in the dog kidney. Circ Res 42:181

15. Reimold EW, Don TD, Worthen HG 1977 Renal failure during the first year of life. Pediatrics 59 (suppl):987

16. Sabto J, Bankir L, Grunfeld JP 1978 The measurement of glomerular blood flow in the rat kidney: influence of microsphere size. Clin Exp Pharmacol Physiol 5:559

17. Spitzer A, Brandis M 1974 Functional and morphologic maturation of the superficial nephrons: relationship to total kidney function. J Clin Invest 53:279

18. Taki M, Goldsmith DI, Spitzer A 1983 Impact of age on effects of ureteral obstruction on renal function. Kidney Int 24:602

19. Warshaw BL, Hymes LC, Woodard JR 1982 Long-term outcome of patients with obstructive uropathy. Pediatr Clin N Am 29:815

20. Wright FS 1982 Effects of urinary tract obstruction on glomerular filtration rate and renal blood flow. Semin Nephrol 2:5

21. Yarger WE, Schocken DD, Harris RH 1980 Obstructive nephropathy in the rat: possible roles for the renin-angiotensin system, prostaglandins, and thromboxanes in postobstructive renal function. J Clin Invest 65:400

\title{
Chronic Partial Ureteral Obstruction in the Neonatal Guinea Pig. II. Pressure Gradients Affecting Glomerular Filtration Rate
}

\author{
ROBERT L. CHEVALIER \\ With the technical assistance of Anthony V. Broccoli \\ Department of Pediatrics, University of Virginia School of Medicine, Charlottesville, Virginia 22908
}

\begin{abstract}
Neonatal guinea pigs with chronic partial ureteral obstruction (CPUO) and contralateral nephrectomy develop hydroureteronephrosis and reduced glomerular filtration rate (GFR) without significant reduction of renal blood flow. To investigate the role of pressure gradients in determination of GFR, micropuncture studies were performed in animals $23 \pm 3$ days of age subjected to
\end{abstract}

Received March 12, 1984; accepted May 22, 1984.

Requests for reprints should be addressed to Robert Chevalier, M.D., Department of Pediatrics, Box 386, University of Virginia Medical School, Charlottesville, Virginia 22908.

This work was supported by National Institutes of Health Grant 5 S07 RR 05431-21, by a Grant-in-Aid from the American Heart Association, and with funds contributed in part by the American Heart Association, Virginia Affiliate. R.L.C. is an Established Investigator of the American Heart Association. This study was presented in part at the Second International Workshop on Developmental Renal Physiology, Marburg, West Germany, August 27, 1983, and at the 6th Internationa Pediatric Nephrology Symposium, Hanover, West Germany, September 1, 1983. left ureteral constriction and right nephrectomy within the first 2 days of life and compared to uninephrectomized controls. Resulting ureteral dilatation was variable, with kidney weight and ureteral diameter being proportional to the rise in ureteral pressure $\left(P_{U}\right)$. In individual animals with severe CPUO (ureteral diameter $\geq 3 \mathrm{~mm}$ ), distal tubular transit time was either normal (31-90 s) or prolonged (>120 s). Superficial single nephron GFR (SNGFR) was inversely correlated with $\boldsymbol{P}_{U}$.

Glomerular capillary pressure and afferent arteriolar colloid oncotic pressure were not affected by CPUO while peritubular capillary, proximal and distal intratubular hydrostatic pressure increased as a function of $P_{U}$. As a result, afferent effective filtration pressure $\left(\boldsymbol{E F P} \boldsymbol{P}_{A}\right)$ was reduced in severe $(10.0 \pm 1.1 \mathrm{~mm} \mathrm{Hg})$ compared to mild CPUO (13.4 $\pm 0.5 \mathrm{~mm} \mathrm{Hg}$ ), but was not different from controls (11.3 $\pm 0.9 \mathrm{~mm} \mathrm{Hg}$ ). For both control and CPUO groups, 
superficial SNGFR increased by $0.5 \mathrm{nl} / \mathrm{min}$ for each $\mathrm{mm}$ $\mathrm{Hg}$ increase in $E F P_{A}$ but for a given $E_{F P}$, SNGFR was 6 $\mathrm{nl} / \mathrm{min}$ lower in guinea pigs with CPUO. These results indicate that higher $\boldsymbol{E F P}_{A}$ in animals with mild compared to severe CPUO contributes to maintenance of higher SNGFR. However, a $70 \%$ reduction in superficial SNGFR for guinea pigs with severe CPUO is due in large part to reduced ultrafiltration coefficient. The mechanisms whereby chronically elevated $\boldsymbol{P}_{U}$ in the neonate result in these complex changes of glomerular dynamics may relate to altered intrarenal production of vasoactive hormones. (Pediatr Res 18:1271-1277, 1984)

\section{Abbreviations}

CPUO, chronic partial ureteral obstruction

$E F P_{A}$, afferent effective filtration pressure

GFR, glomerular filtration rate

$P_{D T}$, distal intratubular hydrostatic pressure

$\boldsymbol{P}_{G C}$, glomerular capillary pressure

$\boldsymbol{P}_{P T}$, proximal intratubular hydrostatic pressure

$\boldsymbol{P}_{S F}$, stop-flow pressure

$P_{U}$, intraureteral pressure

SNGFR, single nephron glomerular filtration rate

Unilateral chronic partial ureteral obstruction in the neonatal guinea pig results in hemodynamic changes which are dependent on the severity of obstruction and influenced by the presence or absence of the contralateral kidney (6). Unlike animals with the opposite kidney in place, in which severe CPUO results in elevated renal vascular resistance, those uninephrectomized at birth have little decrease in renal blood flow although GFR was reduced by approximately $50 \%$ (6). Because these guinea pigs have marked hydroureteronephrosis suggesting increased intraureteral hydrostatic pressure, the present study was designed to evaluate the role of pressure gradients influencing GFR in this model. As animals with contralateral nephrectomy and severe CPUO were azotemic despite compensatory renal hypertrophy, this group was chosen for further study because functional adaptation to CPUO would be expected to be maximal in an effort to maintain homeostasis.

While previous studies of glomerular dynamics during CPUO have been performed in adult rats with mild ureteral obstruction and intact contralateral kidney $(13,22)$, there are no published reports of glomerular dynamics in CPUO during early development. The guinea pig was chosen for the present experiments because like the human, all nephrons are formed at the time of birth and functional maturation of the superficial nephrons is normally accelerated during the 3rd and 4th weeks of life $(3,21)$. This process is further augmented by uninephrectomy at birth (2-4). Micropuncture techniques were used to examine superficial single nephron function during this dynamic period in which the kidney was responding to the combined influence of rapid somatic growth, reduced renal mass, and CPUO.

\section{MATERIALS AND METHODS}

Thirty-six Hartley guinea pigs were anesthetized with halothane within the first $48 \mathrm{~h}$ of life. All animals were subjected to right nephrectomy and in 28 guinea pigs a 2-mm length of PE60 polyethylene tubing was placed around the distal third of the left ureter. The ureter was left untouched in remaining guinea pigs to serve as controls. At 18-30 days of age, animals were anesthetized with intraperitoneal sodium pentobarbital, $3 \mathrm{mg} / 100 \mathrm{~g}$ body weight and placed on a thermostatically controlled heating table. Tracheostomy was performed, and $0.9 \%$ saline was infused through a jugular vein at $0.3 \mathrm{ml} / 100 \mathrm{~g}$ body weight. Forty-five min before beginning tubular fluid collections, $\left[{ }^{3} \mathrm{H}\right]$ inulin (New
England Nuclear, Boston, MA) was added to the saline infusate in a concentration of $100 \mu \mathrm{Ci} / \mathrm{ml}$. Donor guinea pig plasma was infused through the contralateral jugular vein at $0.9 \pm 0.1 \mathrm{ml} / \mathrm{h}$, adjusted to maintain constant hematocrit (2). Blood pressure was continuously monitored by means of a Statham 23ID pressure transducer connected to a carotid artery catheter.

The left kidney was prepared for micropuncture as previously described for this laboratory (2), and was bathed in $0.9 \%$ saline maintained at $39 \pm 0.5^{\circ} \mathrm{C}$. During maintenance of euvolemia as described above, external ureteral diameter was measured halfway between kidney and bladder using calipers under microscopic visualization. A flared polyethylene cannula was sutured into the bladder for collection of urine in a small weighed cup. As a result of urinary sediment formation, five animals developed acute complete ureteral obstruction during surgical preparation. In these guinea pigs, a fine PE10 polyethylene tube was threaded into the ureter such that the tip lay proximal to the stenosis, allowing urinary flow during the experiment. The resistance to urine flow through the cannula $\left(0.70 \pm 0.36 \mathrm{~mm} \mathrm{Hg} / \mathrm{ml} \mathrm{min} \mathrm{min}^{-1}\right)$ was not different from that in remaining guinea pigs with CPUO $\left(0.42 \pm 0.10 \mathrm{~mm} \mathrm{Hg} / \mathrm{ml} \mathrm{min}^{-1}\right)$ and results were therefore combined. Two to four serial timed urine collections, approximately 30 min each, were obtained throughout the experiment. Blood samples $(100 \mu \mathrm{l})$ were drawn from the arterial catheter at the beginning and end of each urine collection period and were replaced by an equal volume of donor blood. Hematocrit was measured in heparinized capillary tubes.

In each animal, five to eight superficial proximal and distal convoluted tubules were identified by intratubular injection of FD \& C green dye using sharpened $2-\mu \mathrm{m}$ micropipettes. Distal tubular transit time was measured from the time of disappearance of dye from the last visible loop of a proximal tubule to the time of reappearance in the first superficial distal tubular segment. Free flow hydrostatic pressure was then measured in identified proximal $\left(P_{P T}\right)$ and distal tubules $\left(P_{D T}\right)$ as well as in adjacent peritubular capillaries $\left(P_{C}\right)$ using a servo-nulling apparatus and sharpened $2-$ to $4-\mu \mathrm{m}$ micropipettes containing $2 \mathrm{M}$ $\mathrm{NaCl}$. Using sharpened $8-10-\mu \mathrm{m}$ siliconized micropipettes, two to six timed tubular fluid collections were then obtained from last accessible proximal tubular loops identified by dye injection by maintaining an oil block in constant position as previously described (2). Intratubular hydrostatic pressure was monitored during tubular fluid collection by means of a second 2-4- $\mu \mathrm{m}$ micropipette inserted upstream. As initiation of tubular fluid collection almost always resulted in decreased intratubular pressure, counterpressure was applied to the collection pipette to maintain the original pressure in approximately half of the measurements. In guinea pigs with severe ureteral obstruction, superficial proximal tubules varied from normal-appearing to grossly distended with diameters twice the normal size. In these animals, an attempt was made to obtain tubular fluid collections from both types of tubules, identified by distal transit time less than or $\geq 120 \mathrm{~s}$. Stop-flow hydrostatic pressure was then measured in the same nephrons in the first accessible loop of the proximal tubule using a $2-4-\mu \mathrm{m}$ micropipette while a second micropipette with outer diameter of $12-15 \mu \mathrm{m}$, containing Sudan black-stained castor oil, was used to block tubular fluid flow for 2-3 min. Intraureteral pressure was then measured proximal to the stenosis using an $8-10-\mu \mathrm{m}$ micropipette. Penetration of the pipette tip into the ureteral lumen was ascertained by appearance of typical peristaltic pressure waves on the graphic record. Mean intraureteral pressure was measured between peristaltic peaks. The kidney was decapsulated, drained, weighed, and bisected. Half of the kidney was fixed in $10 \%$ formalin solution while the remaining half was dried at $40^{\circ} \mathrm{C}$ for 10 days for calculation of dry/wet ratio.

The volume of tubular fluid collections was measured using à filar eyepiece micrometer (Gaertner, Chicago, IL) after the sample was transferred to a constant-bore capillary tube. Samples of plasma, urine, and tubular fluid were placed in vials containing $0.5 \mathrm{ml}$ water and $5 \mathrm{ml}$ PCS solubilizer (Amersham/Searle) for 
counting of ${ }^{3} \mathrm{H}$ in a liquid scintillation spectrometer (Beckman Instruments, Fullerton, CA). Plasma protein concentration was measured by the Lowry technique (19).

Calculations. Superficial SNGFR was calculated as SNGFR = $(T F / P)_{i n} \times V_{T F}$ where $(T F / P)_{i n}$ is tubular fluid-to-plasma inulin concentration ratio and $V_{T F}$ is tubular fluid flow rate.

Afferent arteriolar colloid oncotic pressure was calculated from the measured plasma protein concentration using the relationship derived by Landis and Pappenheimer (18). Glomerular capillary pressure, afferent hydrostatic pressure gradient for ultrafiltration, and afferent effective filtration pressure were calculated as described previously (5).

Ureteral resistance was calculated as $R_{U}=P_{U} / V$ where $V=$ urine flow rate.

Statistical analysis. Comparison between groups was performed by two-way analysis of variance and Duncan's multiple range test. Comparison of measurements of SNGFR with or without counterpressure, was evaluated by Student's $t$ test for paired data. Linear regression analysis was performed by the method of least squares. Using a linear model (S.A.S. Institute, Cary, NC), the response characteristics of SNGFR to change in $E F P_{A}$ were examined for CPUO and uninephrectomy control groups (17). Components of the model tested were group effects (treatment group), linear effects (variation with $E F P_{A}$ ), and difference of slopes between groups. Comparison of the distribution of distal transit time between groups was accomplished by the Mann-Whitney test statistic.

\section{RESULTS}

As shown in the top panel of Figure 1, somatic growth was impaired in proportion to the rise of intraureteral pressure, which varied from 0 to $16 \mathrm{~mm} \mathrm{Hg}$ although uniform ureteral constriction was initially produced in each animal. Wet kidney weight increased linearly with intraureteral pressure, and because dry/ wet kidney weight ratio was constant at approximately 0.2 for all animals with CPUO, the relationship was similar for dry kidney weight $(r=0.55, p<0.01)$. Ureteral diameter proximal to the stenosis correlated closely with intraureteral pressure, which in turn reflects intrapelvic pressure. Animals with ureteral diameter less than $3 \mathrm{~mm}$ were classified as "mild CPUO." Guinea pigs with ureteral diameter of at least $3 \mathrm{~mm}$ had visible dilatation of the renal pelvis, a tortuous, convoluted ureter, and were classified as "severe CPUO."

Although tubular diameter was not quantitated, inspection of the kidney surface revealed that tubules with transit time exceeding $120 \mathrm{~s}$ were invariably more dilated than adjacent tubules with shorter transit time. As shown in Figure 2, 74\% of distal transit times in the control group fell between 31 and $90 \mathrm{~s}$. Surprisingly, while $80 \%$ of transit times in the mild CPUO group were in the same range, median transit time was $57.5 \mathrm{~s}$ compared to $66.0 \mathrm{~s}$ in controls $(p<0.05)$. In severe CPUO, $50 \%$ of transit times were greater than $120 \mathrm{~s}$, while $45 \%$ were 31 to $90 \mathrm{~s}$.

There was no difference in initial hematocrit between control $(41.1 \pm 0.7)$ and CPUO $(40.3 \pm 0.6)$ groups. At the end of the experiment, hematocrit was $40.4 \pm 1.6$ in control and $39.3 \pm 0.8$ in CPUO groups. Plasma inulin concentration varied $16.6 \pm$ $3.5 \%$ between first and last blood samples. Plasma total protein concentration was not different between groups, averaging 5.40 \pm 0.12 and $5.06 \pm 0.13 \mathrm{~g} / \mathrm{dl}$ in control and CPUO groups, respectively. Variability in urine flow between first and last urine collections averaged $17.1 \pm 3.0 \%$. Urine flow was $15.6 \pm 5.2 \mu \mathrm{l} /$ $\mathrm{min}$ in control animals and $14.1 \pm 2.4 \mu \mathrm{l} / \mathrm{min}$ in those with ureteral obstruction (not significant), while resistance to urine flow was $0.02 \pm 0.02$ and $0.49 \pm 0.11 \mathrm{~mm} \mathrm{Hg} / \mu 1 \mathrm{~min}^{-1}$ in control and CPUO groups, respectively $(p<0.05)$. Although microscopic examination revealed no leukocytes or bacteria, a cloudy sediment of amorphous crystals was present in the urine of animals with ureteral obstruction. The sediment was most concentrated in the group with severe CPUO.

As shown in Figure 3, mean superficial SNGFR measured
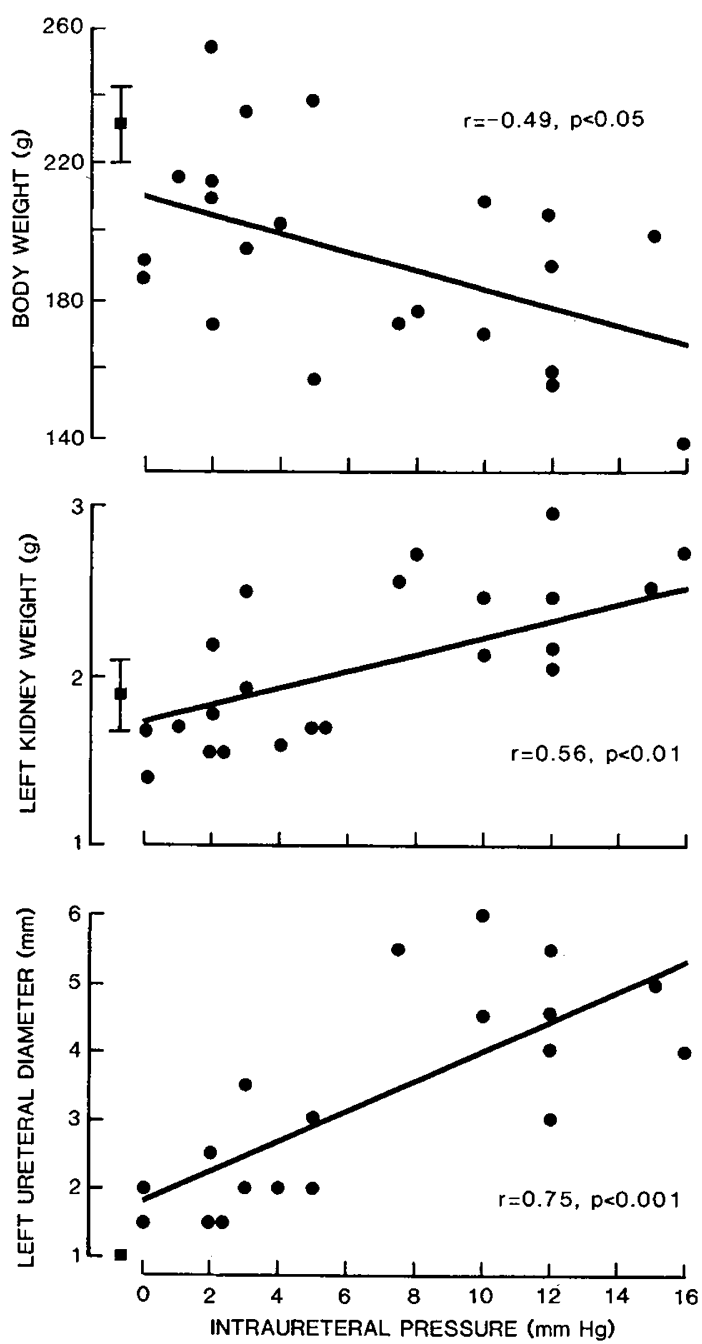

Fig. 1. Top panel: body weight versus intraureteral pressure; $y=$ $-2.81 x+211$. Middle panel: left kidney weight versus intraureteral pressure; $y=0.05 x+1.73$. Lower panel: left ureteral diameter versus intraureteral pressure; $y=0.22 x+1.81$. 9 , values for animals with CPUO and the regression line is for all animals with CPUO. $\square$, mean \pm $\mathrm{SE}$ for control uninephrectomized animals.

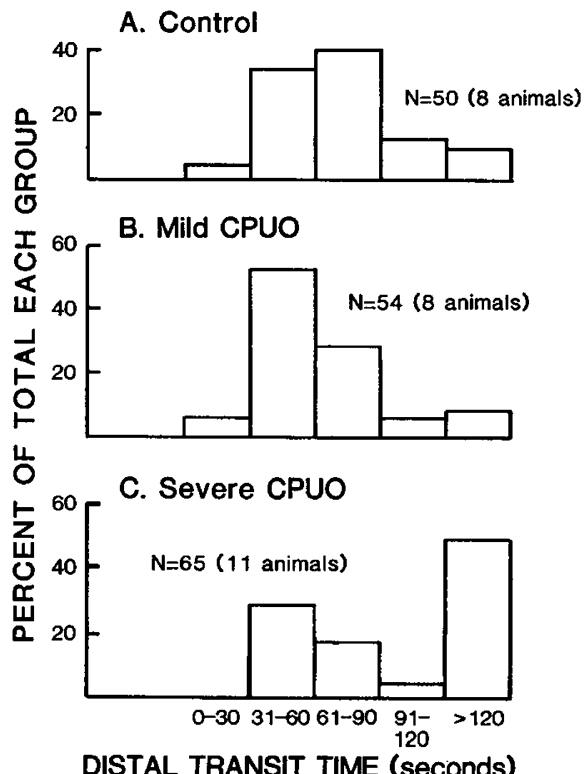

Fig. 2. Distal transit time for each group. $N$, number of observations in each group. 
during maintenance of initial $P_{T}$ was inversely correlated with intraureteral pressure. Due to technical difficulties in obtaining at least two tubular fluid collections during application of counterpressure in nephrons previously subjected to micropressure measurements, only 11 animals are represented in the experimental group. In both control and CPUO groups, SNGFR was significantly higher when tubular fluid was collected by free flow than during maintenance of initial $P_{P T}$ by counterpressure $(p<$ 0.001 ) (Table 1). Paired determinations of SNGFR with and without counterpressure by recollection from the same nephron in three control and three CPUO animals revealed a difference in SNGFR of $3.0 \pm 0.7 \mathrm{nl} / \mathrm{min}(n=8$ pairs, $p<0.001)$, and in $P_{P T}$ of $4.7 \pm 0.6 \mathrm{~mm} \mathrm{Hg}(p<0.001)$. The $(T F / P)_{\text {in }}$ ratio was not different during free flow collections betweeen control (1.38 \pm $0.07)$ and CPUO $(1.36 \pm 0.06)$ groups. Furthermore, there was no effect of counterpressure on $(T F / P)_{i n}$.

The effect of $P_{P T}$ to oppose filtration was thus more marked in severe CPUO wherein $P_{P T}$ as well as $P_{D T}$ were increased at $P_{U}$ greater than $5 \mathrm{~mm} \mathrm{Hg}$ (Table 1, Fig. 4). There was no effect of increasing $P_{U}$ on either mean arterial pressure or glomerular capillary pressure, but peritubular capillary pressure was significantly correlated with severity of CPUO (Fig. 4). To determine

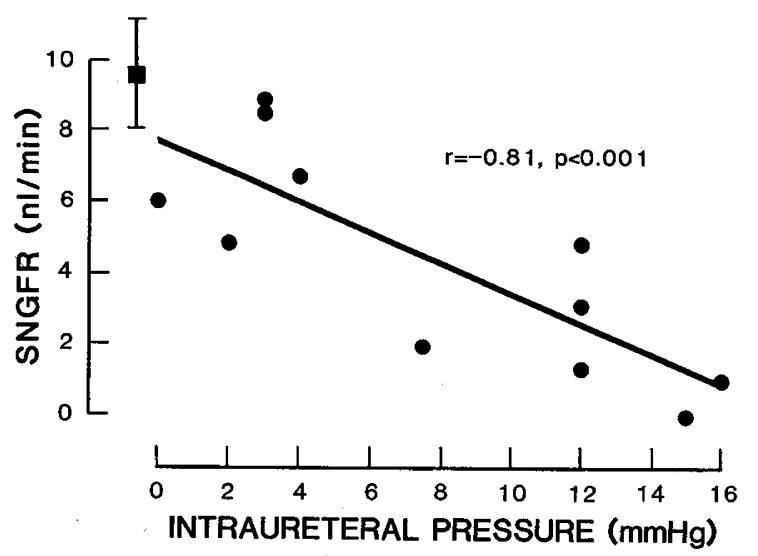

Fig. 3. Single nephron glomerular filtration rate measured during maintenance of initial proximal intratubular hydrostatic pressure, as a function of intraureteral pressure; $y=-0.43 x+7.68$. 9 , mean of two to eight determinations for one animal with CPUO and the regression line is for animals with CPUO. $\square$, mean \pm SE for control uninephrectomized animals.

Table 1. Micropuncture data*

\begin{tabular}{lccc}
\hline & $\begin{array}{c}\text { Control } \\
\text { uninephrectomy }\end{array}$ & $\begin{array}{c}\text { Mild } \\
\text { CPUO }\end{array}$ & $\begin{array}{c}\text { Severe } \\
\text { CPUO }\end{array}$ \\
\hline $\begin{array}{l}\text { SNGFR (nl/min) } \\
\text { With counter- }\end{array}$ & $9.63 \pm 1.55$ & $8.21 \pm 1.72$ & $2.99 \pm 1.11 \dagger$ \\
pressure & $(5)$ & $(5)$ & $(7)$ \\
No counterpres- & $13.39 \pm 1.42$ & $9.77 \pm 1.75$ & $5.11 \pm 1.32 \dagger$ \\
$\quad$ sure & $(5)$ & $(5)$ & $(5)$ \\
Pressure (mmHg) & & & \\
$\quad$ Mean arterial & $62.9 \pm 2.5$ & $62.6 \pm 2.3$ & $63.6 \pm 2.9$ \\
Glomerular cap- & $38.7 \pm 0.8$ & $39.3 \pm 1.4$ & $39.6 \pm 1.4$ \\
$\quad$ illary & & & \\
Proximal tubule & $10.5 \pm 0.4$ & $10.0 \pm 0.4$ & $13.8 \pm 0.4 \dagger \ddagger$ \\
$\begin{array}{l}\text { Distal tubule } \\
\text { Peritubular cap- }\end{array}$ & $7.3 \pm 0.3$ & $8.6 \pm 0.7$ & $10.5 \pm 0.4 \dagger \neq$ \\
$\quad$ illary & $4.5 \pm 0.2$ & $4.7 \pm 0.2$ & $5.3 \pm 0.4$ \\
Ureteral & & & \\
Afferent effective & $11.3 \pm 0.9$ & $13.4 \pm 0.5$ & $10.2 \pm 1.1 \dagger \ddagger$ \\
$\quad$ filtration pres- & $(8)$ & $(10)$ & $(12)$ \\
sure & & & \\
\hline
\end{tabular}

${ }^{*}$ Values are mean $\pm \mathrm{SE}$ (number of animals in parentheses).

$\dagger p<0.05 v s$. control.

$\ddagger p<0.05$ vs. mild CPUO. $\mathrm{mm} \mathrm{Hg}$
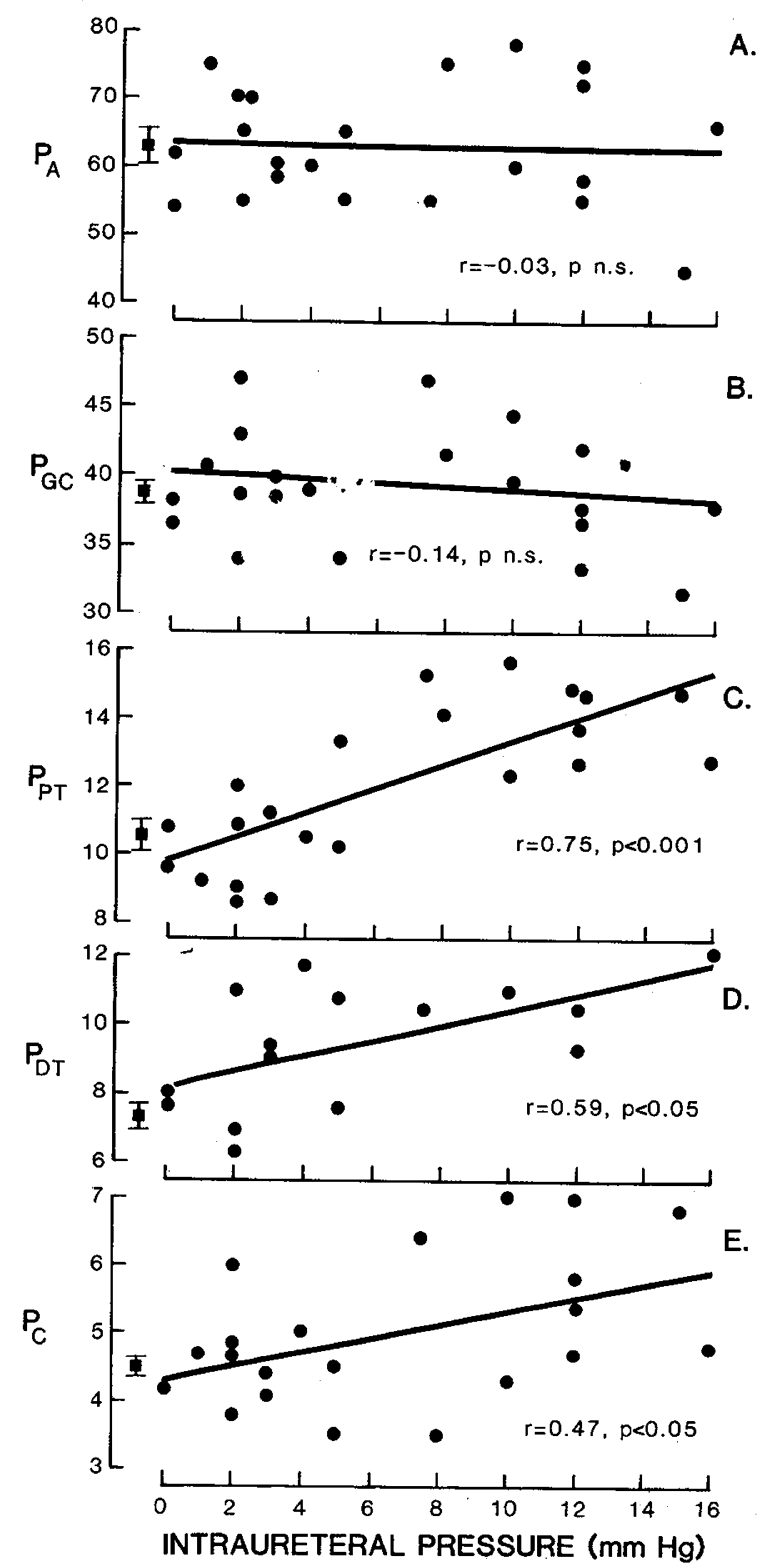

Fig. 4. Hydrostatic pressure determinations versus intraureteral pressure. $A, P_{A} ; y=0.05 x+63 . B, P_{G C} ; y=-0.12 x+40 . C, P_{P T} ; y=0.34 x$ +9.8. $D, P_{D T} ; y=0.22 x+8.2$. $E, P_{C} ; y=0.10 x+4.3$. Symbols are the 'same as in Figure 3.

whether prior tubular fluid collection altered $P_{S F}$ measurement in the same nephron, deteminations of $P_{S F}$ pressure in nephrons both with and without prior tubular fluid collection were made in nine guinea pigs with CPUO. The result did not differ between nephrons with previous tubular fluid collection $\left(P_{S F}=21.5 \pm\right.$ $1.0 \mathrm{~mm} \mathrm{Hg})$ and those without $(22.2 \pm 1.2 \mathrm{~mm} \mathrm{Hg})$.

Oncotic and hydrostatic pressure gradients affecting glomerular ultrafiltration are shown in Figure 5. Afferent colloid oncotic pressure did not change as a result of CPUO, while the transcapillary hydrostatic pressure gradient (and consequently $E F P_{A}$ ) was reduced in animals with severe CPUO. The relationship of SNGFR to $E F P_{A}$ for each group is shown in Figure 6. There is a significant correlation between the two variables in control and CPUO groups, and the slope does not differ between groups. However, the $y$ axis intercept of the regression line is $6 \mathrm{nl} / \mathrm{min}$ higher for control than obstructed animals $(p<0.001)$. 

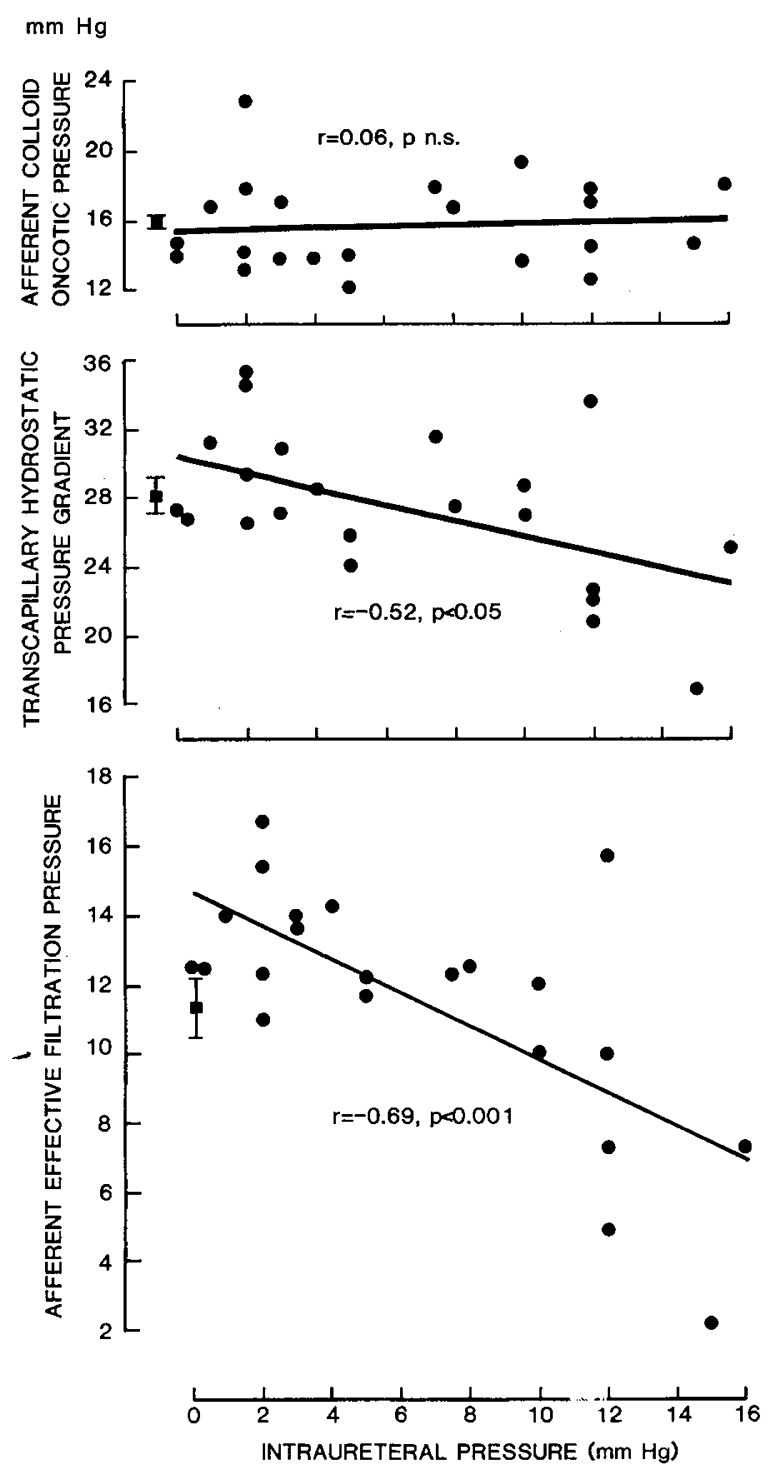

Fig. 5. Pressure gradients affecting glomerular ultrafiltration versus intraureteral pressure. Top panel: oncotic pressure; $y=0.03 x+15.6$. Middle panel: hydrostatic pressure; $y=-0.46 x+30.4$. Lower panel: afferent effective filtration pressure; $y=-0.48 x+14.7$. Symbols are the same as in Figure 3.

\section{DISCUSSION}

Technical considerations. Whole kidney GFR could not be accurately measured by inulin clearance in animals with CPUO because of the significant dead space created by a dilated renal pelvis and ureter proximal to the obstruction, as well as possible inulin leakage across obstructed tubules (20). As the proximal tubule was proportionately less dilated by CPUO than distal tubule or collecting system, and as measured $(T F / P)_{\text {in }}$ ratio was not altered by CPUO in the present study, superficial SNGFR could be measured in each group by tubular fluid collections. However, these experiments show that by reducing $P_{P T}$, free flow proximal tubular fluid collection overestimates SNGFR in the developing guinea pig. By maintaining the initial $P_{P T}$ with application of counterpressure during tubular fluid collection, this variable could be controlled.

In the present study, $P_{G C}$ was calculated from $P_{S F}$ rather than directly measured, because of the paucity of surface glomeruli in the guinea pig (5). Measurement of $P_{S F}$ was unaffected by prior tubular fluid collection from the same nephron. However, a recent report suggests that, in the hydropenic adult rat, $P_{G C}$ calculated from $P_{S F}$ may overestimate directly measured $P_{G C}$
(12). Others have not confirmed these findings (15). Furthermore, Kaskel et al. (16) have demonstrated a close correlation between $P_{G C}$ calculated from $P_{S F}$ and that measured by direct puncture of glomerular capillaries in guinea pigs $2 \mathrm{~h}$ to 10 days old. Arendshorst et al. (1) have also shown no difference in $P_{G C}$ measured by the two techniques either in control hydropenic rats or in animals with markedly elevated $P_{P T}$ as a result of temporary renal ischemia. Wright (23) maintains that $P_{S F}$ is a reliable indicator of $P_{G C}$, as changes in directly measured $P_{G C}$ during complete unilateral ureteral obstruction in the rat closely parallel changes observed in $P_{S F}$. Taken together, experimental evidence thus strongly supports the use of $P_{S F}$ for determination of $P_{G C}$ in the developing guinea pig with CPUO.

Effects of intraureteral pressure on $S N G F R$. While ureteral obstruction at birth resulted in intraureteral pressure varying from normal to significantly elevated measurements at $3 \mathrm{wk}$ of age, all animals had ureteral dilatation proportional to $P_{U}$. Progressive ureteral dilatation following ureteral obstruction in early development is due to hyperplasia of leiomyocytes (8) and deposition of connective tissue after 2 wk of CPUO (9). A significant correlation of $P_{U}$ with kidney weight and an inverse correlation with body weight implies that several morphometric correlates of CPUO in the neonate are directly or indirectly related to continued intraureteral pressure elevation. Dependence of intratubular pressure on urine flow is well established in the normal kidney (11) and would be accentuated by the increased ureteral resistance in guinea pigs with CPUO. As hematocrit and plasma total protein concentration were maintained constant in the present study, intravascular volume presumably remained unchanged during the experiment, and measured $P_{U}$ reflects that present at normal urine flow rates. The close negative correlation between $P_{U}$ and superficial SNGFR indicates that factors leading to $P_{U}$ elevation are also important determinants of ultrafiltration in neonatal CPUO. As maturation of superficial nephrons takes place most rapidly in the guinea pig between 2 and 4 wk of age (21), it is possible that functional development is more easily disrupted in outer than inner glomeruli when CPUO is present at this time. The observed decrease in superficial SNGFR also parallels a shift in renal blood flow distribution from outer to inner cortex with severe CPUO in uninephrectomized guinea pigs of similar age (6).

A feature which distinguished kidneys of animals with severe CPUO from those with mild obstruction and controls was the marked heterogeneity of tubular fluid flow rate measured by distal transit time. Rather than forming a graded continuum, however, there appear to be two distinct populations of nephrons in severe CPUO: one with normal and another with prolonged transit time. Increased heterogeneity of SNGFR and nonfiltering nephrons have also been observed following unilateral complete ureteral obstruction (7), or unilateral CPUO (22). As the number of glomeruli perfused per kidney does not change with severity of CPUO in uninephrectomized guinea pigs (6), it is unlikely that heterogeneous nephron function is directly due to hemodynamic factors.

Effects of intraureteral pressure on glomerular dynamics. Arterial blood pressure and $P_{G C}$ were unaffected by CPUO and cannot be responsible for diminished SNGFR. As both $P_{D T}$ and $P_{P T}$ increased with elevation of intraureteral pressure due to CPUO, pressure in Bowman's space presumably rose proportionately.

Peritubular capillary hydrostatic pressure also rose with increasing $P_{U}$. This may have been due to vascular compression by dilated tubules $(10,14)$ or to increased postglomerular blood flow resulting from lower filtration fraction (6). Animals with mild CPUO presumably failed to demonstrate a rise in $P_{P T}$ and $P_{D T}$ because elevation of $P_{U}$ in the normal animal does not affect tubular pressure until preexisting hydrostatic pressure is exceeded (10). As elevation of $P_{U}$ in kidneys with collapsed tubules does not result in elevated $P_{P T}(10)$, hydrostatic pressure is not simply transmitted directly back to the glomerulus, but is altered by 


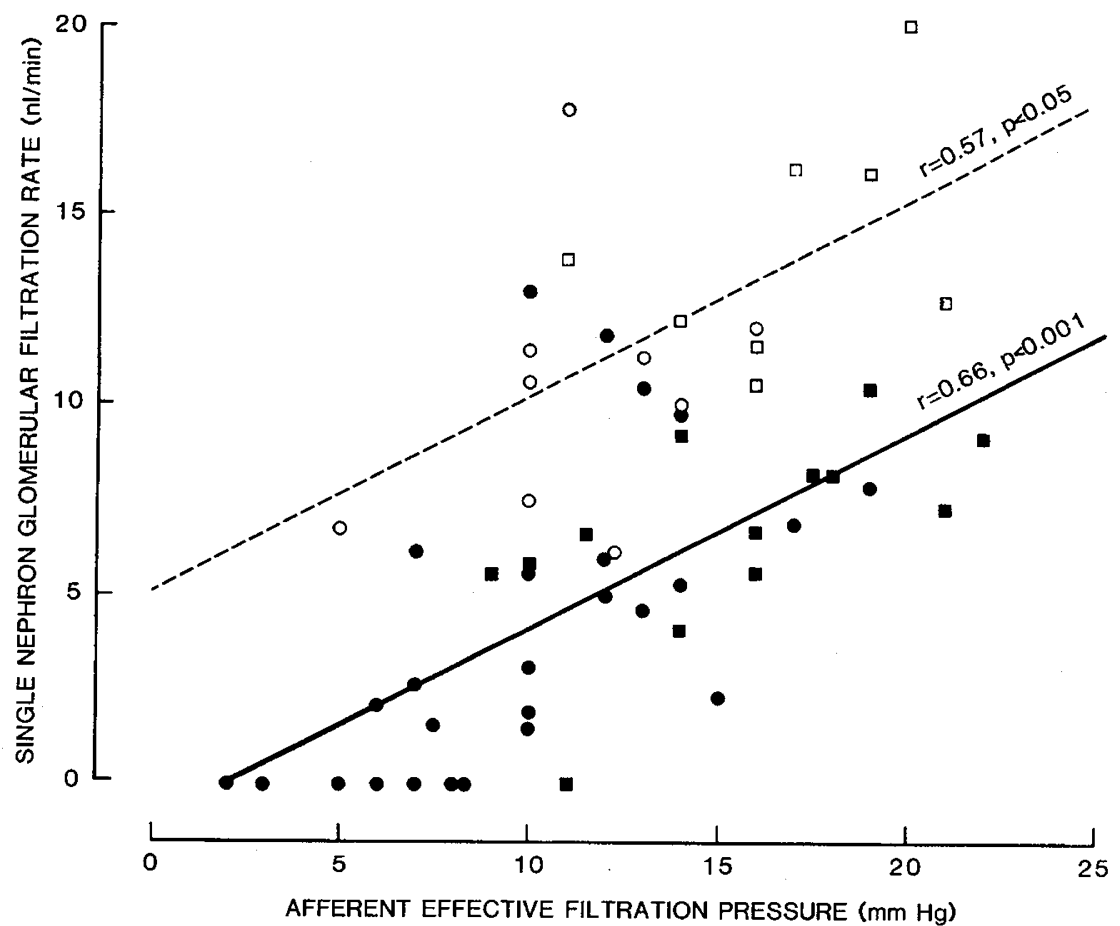

Fig. 6. Single nephron glomerular filtration rate versus afferent effective filtration pressure for individual nephrons. Closed symbols represent measurements in animals with CPUO with regression $(y=0.51 x-1.00)$ given as solid line. Open symbols represent measurements in control uninephretomized animals with regression $(y=0.52 x+5.07)$ depicted by broken line. Circles represent measurements of SNGFR made during application of counterpressure to maintain initial intratubular pressure while squares represent measurements by free flow collection of tubular fluid.

changes in resistance and permeability of each tubular segment. As $P_{P T}$ exceeds $P_{D T}$ in control guinea pigs as well as those with CPUO, the loop of Henle must contribute effective resistance to tubular fluid flow irrespective of the degree of ureteral obstruction. Therefore, just as $P_{U}$ was found to vary widely in animals with originally uniform ureteral obstruction, there may be differences in individual nephron resistance due to variable distortion of Henle's loops despite the fact that all nephrons drain into a pelvis with uniform hydrostatic pressure.

In considering pressure gradients determining ultrafiltration, oncotic and hydrostatic, only the latter were affected by increasing $P_{U}$. The resulting decrease in $E F P_{A}$ in severe compared to mild CPUO suggests that transglomerular pressure gradients contribute significantly to reduced SNGFR in this group. However, when compared to control animals, $E F P_{A}$ was not significantly lower following severe CPUO although SNGFR was reduced by $70 \%$. In both CPUO and control groups, SNGFR increased by $1 \mathrm{nl} / \mathrm{min}$ for each $2 \mathrm{~mm} \mathrm{Hg}$ increment in $E F P_{A}$ although a constant difference in SNGFR of $6 \mathrm{nl} / \mathrm{min}$ at any $E F P_{A}$ points to the influence of the remaining determinants of ultrafiltration: glomerular plasma flow and ultrafiltration coefficient. Results of hemodynamic studies show that renal blood flow tended to be lower in guinea pigs with severe CPUO than in uninephretomized controls, but differences were not signficant (6). For severe CPUO, even when a $6 \%$ redistribution of blood flow from outer to inner cortical levels is taken into account (6), superficial nephron perfusion would be no more than $27 \%$ lower than in controls. The only explanation for severely reduced SNGFR in this group is therefore a decrease in ultrafiltration coefficient of at least $33 \%$. For animals with mild CPUO, in which superficial SNGFR was not different from that in controls, the presumed decrease in ultrafiltration coefficient was counterbalanced by a tendency to higher $E F P_{A}$. Similar conclusions were reached in a study of mild CPUO in the adult rat, in which SNGFR remained normal despite marked reduction in ultrafiltration coefficient (13). In contrast to the neonatal guinea pig, $P_{G C}$ was elevated by CPUO in this study (13).
In summary, CPUO in the uninephrectomized newborn guinea pig results in complex alterations in glomerular dynamics which are related to the severity of elevation in $P_{U}$. Rather than hydrostatic pressure simply being transmitted back to the glomerulus with SNGFR being dependent on net $E F P_{A}$, the effects of increased $P_{U}$ on SNGFR appear to be mediated via subtle hemodynamic changes and reduction in ultrafiltration coefficient. Whether ultrafiltration coefficient is altered primarily by changes in filtration surface area or in glomerular permeability cannot be determined from these data. It is likely that locally produced vasoactive compounds such as angiotensin and prostaglandins are responsible for changes in ultrafiltration coefficient as well as in resistance of the renal microvasculature (13). The interrelationships of renal hormones in the adult kidney are poorly understood, and are even less clear in the developing kidney in which nephron heterogeneity and rapidly changing glomerular dynamics also modulate glomerular filtration rate. Elucidation of mechanisms responsible for the observed effects of CPUO in the neonate will most likely depend on further advances in renal endocrinology.

Acknowledgments. The assistance of Dr. Donald Kaiser in performance of statistical analysis is gratefully acknowledged. Secretarial assistance was provided by Ms. Jean De Piro.

\section{REFERENCES}

1. Arendshorst WJ, Finn WF, Gottschalk CW 1975 Pathogenesis of acute renal failure following temporary renal ischemia in the rat. Circ Res 37:558

2. Chevalier RL 1982 Functional adaptation to reduced renal mass in early development. Am J Physiol 242:F190

3. Chevalier RL 1982 Glomerular number and perfusion during normal and compensatory renal growth in the guinea pig. Pediatr Res 16:436

4. Chevalier RL 1983 Hemodynamic adaptation to reduced renal mass in early postnatal development. Pediatr Res 17:620

5. Chevalier RL 1983 Reduced renal mass in early postnatal development: glomerular dynamics in the guinea pig. Biol Neonate $44: 158$

6. Chevalier RL, Kaiser DL 1984 Chronic partial ureteral obstruction in the neonatal guinea pig: influence of uninephrectomy on growth and hemodynamics. Pediatr Res 18:1266 
7. Clausen G, Hope A 1977 Intrarenal distribution of blood flow and glomerular filtration during chronic unilateral ureteral obstruction. Acta Physiol Scand 100:22

8. Cussen LJ, Tymms A 1972 Hyperplasia of ureteral muscle in response to acute obstruction of the ureter: a quantitative study. Invest Urol 9:504

9. Gee WF, Kiviat MD 1975 Ureteral response to partial obstruction: smooth muscle hyperplasia and connective tissue proliferation. Invest Urol 12:309

10. Gottschalk CW, Mylle M 1956 Micropuncture study of pressures in proximal tubules and peritubular capillaries of the rat kidney and their relation to ureteral and renal venous pressures. Am J Physiol 185:430

11. Gottschalk CW, Mylle M 1957 Micropuncture study of pressure in proximal and distal tubules and peritubular capillaries of the rat kidney during osmotic diuresis. Am J Physiol 189:323

12. Ichikawa I 1982 Evidence for altered glomerular hemodynamics during acute nephron obstruction. Am J Physiol 242:F580

13. Ichikawa I, Brenner BM 1979 Local intrarenal vasoconstrictor-vasodilator interactions in mild partial ureteral obstruction. Am J Physiol 236:F131

14. Jensen PK. Steven K 1979 Influence of intratubular pressure on proximal tubular compliance and capillary diameter in the rat kidney. Pflugers Arch 382:179

15. Kallskog O, Wolgast M 1983 Validity of the stop-flow method for estimating glomerular capillary pressure. Acta Physiol Scand 117:145

16. Kaskel FJ, Kumar AM, Spitzer A 1983 Dynamics of glomerular filtration in developing guinea pig. Pediatr Res 17:352A

17. Kleinbaum DG, Kupper LL 1978 Applied Regression Analysis and Other Multivariable Methods. Duxbury Press, North Scituate, MA, pp 97-102

18. Landis EM, Pappenheimer JR 1962 Exchange of substances through capillary walls. In: Hamilton WF, Dow P (eds). Handbook of Physiology: Circulation, Sect 2, Vol 2. American Physiological Society, Washington, DC, pp 9611034

19. Lowry OH, Rosebrough NJ, Farr AL, Randall RJ 1951 Protein measurement with the Folin phenol reagent. J Biol Chem 193:265

20. McDougal WS, Wright FS 1972 Defect in proximal and distal sodium transport in post-obstructive diuresis. Kidney Int 2:304

21. Spitzer A, Brandis M 1974 Functional and morphologic maturation of the superficial nephrons: relationship to total kidney function. $J$ Clin Invest $53: 279$

22. Wilson DR 1972 Micropuncture study of chronic obstructive nephropathy before and after release of obstruction. Kidney Int 2:119

23. Wright FS 1982 Effects of urinary tract obstruction on glomerular filtration rate and renal blood flow. Semin Nephrol 2:5

\title{
Inotropic Effects of Prostaglandin $D_{2}$ and $E_{1}$ on the Newborn Rabbit Heart
}

\author{
SHIGERU UEMURA, TOSHIO NAKANISHI, SUGURU MATSUOKA, WILLIAM F. FRIEDMAN, \\ AND JAY M. JARMAKANI
}

The Department of Pediatrics, Division of Cardiology, University of California, Los Angeles, Center for the Health Sciences, Los Angeles, California 90024

\begin{abstract}
This study determines the inotropic effects of prostaglandin $\mathrm{D}_{2}\left(\mathrm{PGD}_{2}\right)$ and prostaglandin $\mathrm{E}_{1}\left(\mathrm{PGE}_{1}\right)$ in the isolated, arterial perfused newborn (NB) and adult (A) rabbit heart.

Significant positive inotropism of $\mathrm{PGD}_{2}$ was observed at all concentrations studied $\left(1 \times 10^{-17}\right.$ to $\left.1 \times 10^{-7} \mathrm{M}\right)$ in the two age groups; the effect in the NB was significantly greater $(p<0.05)$ than that in the $A$ at $\mathrm{PGD}_{2}$ concentrations higher than $1 \times 10^{-17} \mathrm{M}$. Significant positive inotropism of $\mathrm{PGE}_{1}$ was observed at $\mathrm{PGE}_{1}$ concentrations higher than $1 \times 10^{-8} \mathrm{M}$ in the $\mathrm{NB}$, and only at $1 \times 10^{-6}$ $M$ in the $A$.

In the $N B$, the relaxation parameters $[1 / 2 \mathrm{RT}$ and the ratio of $+d T / d t(\max )$ to $-d T / d t(\max )]$ decreased to $80 \%$ of control after $\mathrm{PGE}_{1}$ infusion, but not after $\mathrm{PGD}_{2}$ infusion. In contrast, relaxation parameters in the $A$ were not different from control.
\end{abstract}

Propranolol $\left(1 \times 10^{-6} \mathrm{M}\right)$ did not alter the positive inotropic action of $\mathrm{PGD}_{2}$ and $\mathrm{PGE}_{1}$ in the $\mathrm{NB}$. These data indicate that: 1) the positive inotropic effects of $P G D_{2}$ and $\mathrm{PGE}_{1}$ in $\mathrm{NB}$ are greater than that in the $\left.\mathrm{A}, 2\right) \mathrm{PGE}_{1}$ and not $\mathrm{PGD}_{2}$, enhances myocardial relaxation only in the $\mathrm{NB}$,

September 29, 1983; accepted April 13, 1984.

Address reprint requests to Jay M. Jarmakani, M.D., UCLA Medical Center, Department of Pediatrics, Los Angeles, CA 90024.

This work was supported by Research Grants HL-24148 and HL-25476 from The National Heart, Blood, and Lung Institute, and Research Grant 744G1-1 and Group Investigator Award 5061G9 from the American Heart Association, Greater Los Angeles Affiliate.
3) the contractile effects of $\mathrm{PGD}_{2}$ and $\mathrm{PGE}_{1}$ are not mediated by $\beta$-receptors. (Pediatr Res 18:1277-1281, 1984)

\section{Abbreviations}

\author{
$\mathrm{PGE}_{1}$, prostaglandin $\mathrm{E}_{1}$ \\ $\mathrm{PGD}_{2}$, prostaglandin $\mathrm{D}_{2}$ \\ DT, developed tension \\ $\mathrm{RT}$, resting tension \\ $+d T / d t$ (max), maximal rate of tension development \\ $-d T / d t$ (max), maximal rate of relaxation \\ $1 / 2 \mathbf{R T}$, half-relaxation time
}

$\mathrm{PGE}_{1}$ has been used to maintain the patency of the ductus arteriosus in the newborn with ductus-dependent congenital heart disease (9). Recent studies in fetal and newborn lambs (5, 32) showed that $\mathrm{PGD}_{2}$ decreased the pulmonary arteriolar resistance and suggested that $\mathrm{PGD}_{2}$ may be used to treat newborns with persistent pulmonary hypertension $(5,32)$. However, little is known about the inotropic effects of prostaglandins in the newborn. Previous reports of the influence of PGs on myocardial contractility in the adult are inconsistent $(18,19)$. These contradictory results may be due to heart rate variability $(4,34)$, extracellular $\mathrm{Ca}^{2+}$ concentration $\left[\mathrm{Ca}^{2+}\right](20)$, species $(4,19)$, and the experimental preparation $(19,34)$.

This study was designed to determine the action of $\mathrm{PGE}_{1}$ and 